\title{
O Uso de Concepções e Técnicas Administrativas Modernas na Administração Pública
}

Faqir MUHAMMAD

Chief of Section for Development Administration UNITED NATIONS Public Administration Division

Tradução de Araújo Cavalcanti

Fonte: International Review of Administrative Sciences.

Révue Internationale des Sciences Administratives.

Vol. XXXVII, n. ${ }^{\circ} 3,1971$ - Páginas 187/200-IIAS, Brussels.

OBSERVAÇõES: Os pontos de vista expressos neste artigo não coincidem, necessariamente, com os das Nações Unidas, embora - Prof. Faqir Muhammad recorra substancialmente aos documentos e conclusões do Seminário Interregional das Nações Unidas sobre o Emprego dos Modernos Enfoques e Técnicas Administrativas nos Países em Desenvolvimento, realizado em Washington, de 26 de outubro a 6 de novembro de 1970. O Autor serviu, aliás, como Secretário Técnico desse importante Seminário da ONU. Evidentemente, nos limites preestabelecidos de seu trabalho, não cogitou o Prof. F. Muhammad de esgotar a matéria discutida naquele Seminário, permanecendo, todavia, adstrito aos temas básicos que são, de resto, expostos com simplicidade, clareza e rara concisão. É o seguinte o roteiro do artigo ora divulgado pela "Revista do Serviço Público": Introdução, Fontes de Motivação e Impulso, Enfoques e Técnicas Modernas, Utilização no Âmbito da Administração Pública, Técnicas da Ciência do Comportamento, Sistema de Planejamento, Programação e Orçamento (PPBS), Processamento Automático de Dados e Sistemas Informativos Computadorizados, Pesquisa Operacional, Alguns Efeitos Globais e Referências Bibliográficas. Finalmente, a RSP aduziu alguns comentários finais à margem das novas tecnologias na Administração Pública. 


\section{Introdução}

Forças inumeráveis convergem para focalizar a atenção sobre o uso de "concepções e técnicas administrativas modernas" na órbita da administração pública e contribuem, além disso, para transformar esse fato em um dos acontecimentos preponderantes na administração pública dos anos 70 . O objetivo deste artigo é, sucintamente, fazer um ligeiro retrospecto das conseqüências da variedade e mutabilidade dos enfoques e técnicas destinadas à administração pública e, ao mesmo tempo, das exigências mais críticas relativas às transformações que, em conseqüência, nela se verificam, - particularmente nos campos da educação, do treinamento e da pesquisa - a fim de que os desafios impostos pelas novas tecnologias administrativas possam ser enfrentados com exxito e eficazmente utilizadas as oportunidades que elas ensejam. $\mathrm{O}$ artigo tenta proporcionar uma visão de conjunto das forças que estimulam e impulsionam o emprego das modernas concepções $e$ técnicas de gestão no âmbito da administração pública; das características desses novos enfoques e técnicas; das implicações decorrentes de sua introdução quanto aos aspectos de organização e pessoal; e dos pré-requisitos indispensáveis ao seu desenvolvimento, seleção, adaptação, utilização judiciosa e eficaz nos domínios da administração pública. Trata-se de assunto demasiado vasto para ser esgotado nos limites de um breve artigo, motivo pelo qual ao em vez de uma exaustiva análise do problema destacam-se, apenas, alguns dos seus ângulos mais relevantes.

\section{Fontes de Estímulo e Impulso}

Sistemas e técnicas administrativas sempre foram importantes ingredientes na direção e gestão tanto das organizações públicas como de quaisquer outros empreendimentos cooperativos. A administração apresenta inumeráveis facetas, abrangendo, na multiplicidade das superfícies e ângulos que a constituem, os processos de tomada de decisões, planejamento, organização, liderança, direção, coordenação e controle organizacional. São funções administrativas típicas cujo exercício se apóia no emprego eficaz de métodos, técnicas e sistemas administrativos adequados, de que depende. Assim, por exemplo, as técnicas quantitativas de mensuração vinculadas à propriedade da terra, irrigação, escrituração e contabilidade têm profundas raízes na história. Alguma espécie de análise, explícita ou im- 
plícita, sempre fez parte dos processos de tomada de decisões. Princípios de organização e qualidades de liderança foram freqüentemente delineados pelos teóricos, estudiosos e praticantes do passado. Essas práticas e técnicas de gestão sofreram, no decorrer dos tempos, um lento processo de mudança e evolução. Condições vigentes de comparativa estabilidade em muitas sociedades, antes da revolução industrial, capacitaram os sistemas administrativos a uma gradual adaptação de suas práticas. Apesar de ubíqua, a administração permaneceu nebulosa, e mesmo anônima, como importante elemento nos negócios públicos.

O advento da revolução industrial em muitos países modificou o quadro em considerável extensão; apressou o ritmo da mudança e aduziu novas dimensões à administração. As burocracias de grandes dimensões tornaram-se a forma dominante de organização em condições de atender às demandas da industrialização. A administração, principalmente nas empresas de negócios, adquiriu identidade e passou a ser reconhecida como titular de um papel específico atribuindo-se crescente atenção às técnicas de gestão como suporte básico para o eficaz desempenho desse papel. Desenvolveram-se, a seguir, novos sistemas e técnicas de gerência. Surgiram, destarte, a engenharia industrial, a comercialização, a contabilidade de custos e a administração científica, para citar alguns exemplos.

A revolução industrial teve um impacto considerável nas organizações como se pode demonstrar pela preponderância dos movimentos de economia e eficiência na administração pública. Os sistemas administrativos também passaram por rápida expansão ao se defrontarem com os novos problemas. Os governos reagiram, com variáveis graus de vigor, aos problemas que acompanharam os processos e as conseqüências da industrialização, elaborando uma variedade de instrumentos e técnicas para resolvê-los.

Escritórios de patentes, departamentos de indústrias, trabalho e comércio, órgãos normativos, agências regulamentadoras e instituições bancárias, para mencionar apenas alguns exemplos, tornaram-se partes componentes, assaz conhecidas, das estruturas administrativas, na maioria dos países. Esses departamentos desenvolveram procedimentos legais, administrativos e gerenciais, mais ou menos adequados ao desempenho das respectivas funções. Novos sistemas de pessoal e de or- 
çamento foram surgindo e se instalavam simultaneamente com o recrutamento de pessoas capazes de desempenhar as funções emergentes. Isto é, o pessoal capaz de por em vigor mecanismos de controle e de coordenação nos negócios governamentais. A maneira de tratar esses problemas continuou, porém, basicamente fragmentária. O desenvolvimento de enfoques e técnicas de gestão pertinentes à administração pública prosseguiu, no decorrer do tempo, através de uma combinação das necessidades e do acaso.

Trata-se de uma conjunção de forças que, durante um longo período, vinham sendo forjadas, mas que somente ao longo das últimas quatro ou cinco décadas tornam-se carregadas de conseqüências cujo impacto estimulou as virtualidades adaptativas dos sistemas administrativos e tornou imperativa a implantação de enfoques e técnicas mais imaginativas e eficazes. Essas forças foram diversamente classificadas por vários autores. Mas, para os nossos atuais objetivos elas podem ser divididas em seis categorias: 1) revolução científica e tecnológica; II) impulso de aceleração nos negócios humanos; III) nova escala dos problemas; IV) mudanças nas filosofias públicas; V) efeito demonstração dos êxitos científicos; e VI) fermento da criatividade nas ciências sociais. Todas essas forças estão mutuamente interrelacionadas e se reforçam umas às outras. Conjuntamente, elas sublinham a importância da administração nos negócios públicos e proporcionam o estímulo para a adoção de enfoques e técnicas da administração moderna.

A revolução científica e tecnológica cedo evidenciou-se como a força mais penetrante dos negócios humanos. Ciência e tecnologia são, de fato, as grandes forças motrizes de desenvolvimento material e impacto social. O progresso material realizado pelos países industrialmente desenvolvidos se apóia, basicamente, na ciência e na tecnologia. Os países em desenvolvimento desejam realizar progresso semelhante e melhorar seus respectivos padrões de vida. De acordo com um relatório "O crescente hiato entre a quantidade e a aplicação de pesquisa científica nos paises desenvolvidos e em desenvolvimento, e entre os seus níveis de tecnologia, avulta como um dos maiores fatores da depressão cada vez maior no concernente aos respectivos padrões de vida". 1

Os paises em desenvolvimento desejam-aumentar suas possibilidades e aptidões científicas e tecnológicas a fim de 
atingir metas de desenvolvimento econômico e social. Os mais importantes patrocinadores e veículos desse processo são os Governos, resultando desse fato que as conseqüências diretamente emanadas do impacto das ciências e tecnologias tornam-se preocupações absorventes nos negócios públicos.

Os países industrialmente desenvolvidos, por outro lado, estão ficando preocupados com a orientação e os irreprimiveis avanços da ciência e da tecnologia. Em relatório dirigido ao Presidente dos Estados Unidos o National Goals Research Staff declarou que "na metade da década passada, os cientistas e seu trabalho começaram a sofrer rudes ataques como resultado de sua associação com os militares e com a tecnologia industrial responsável pela poluição ambiental. ${ }^{2}$ Comentando acerca da emergência de novas atitudes em face da ciência, aquele Relatório menciona, também, as assustadoras implicações das armas nucleares e a crescente preocupação a respeito das conseqüências potenciais de tais descobertas cientificas, como por exemplo, a manipulação genética". ${ }^{3}$

A tecnologia - ou seja, a aplicação dos conhecimentos científicos aos assuntos, negócios ou casos concretos, - está sendo, da mesma maneira, submetida a um processo de revisão. No citado Relatório, afirma-se, ainda: "no passado as diretrizes para aplicação da ciência eram algo limitadas: ... decisões do mercado para determinação do valor comercial; a regulamentação governamental para estabelecimento da segurança, preservação da equidade e dos direitos humanos". Agora, a tecnologia é responsabilizada pela deterioração verificada em certos aspectos da qualidade da vida. Efeitos nocivos colaterais decorrentes de inovações progressistas, tais como exemplificados pela história do DDT, práticas abusivas como a poluição de lagos e correntes, e certas tendências sociais, como o rápido crescimento populacional e concentração de gente nas maiores cidades e respectiva periferia, conduziram a uma séria reflexão e reavaliação crítica do impacto social da tecnologia. Nos Estados Unidos originaram um movimento descrito como tributação tecnológica. ${ }^{4}$ Isto envolve avaliação do espectro acumulado das conseqüências resultantes dos desenvolvimentos tecnológicos, incluindo "a derivação e uso de medidas de valor social pertinentes à qualidade da vida", em adição aos critérios convencionais de riscos e benefícios econômico-sociais". 5 
Associado à revolução científica e tecnológica encontra-se o denominado "impulso acelerador" nos negócios humanos. Isto se evidencia através do crescimento populacional explosivo, da efervescente e excessiva urbanização, do consumo de energia, do crescimento econômico dos países industrializados, dos avanços tecnológicos e assim por diante. As forças gêmeas de aceleração e da explosão científica provocam uma desorientação nas pessoas que foi denominada por Alvim Toffler "o choque do futuro". " Poder-se-ia dizer o mesmo acerca das organizações que se revelam inadequadas ou incapazes diante dos múltiplos problemas do desenvolvimento econômico e social. Aquele "impulso acelerador" é mais visível nos países como os Estados Unidos, nos quais os impactos da tecnologia têm sido mais espetaculares. Esse estado de coisas induziu muitos observadores a caracterizarem os Estados Unidos como "uma sociedade provisória". Sustenta-se que a taxa de mudança social é tão grande nesse país que ele se transformaria em uma outra sociedade num período de tempo relativamente curto, digamos, 10 ou 15 anos. Afirma-se, também, que as organizações produtivas e, no seu bojo, os padrões de funcionamento das associações e dos papéis individuais sofrerão drásticas mudanças. 7 Autores como Drucker sustentam que as indústrias predominantes já não mais serão os nervos motores básicos do crescimento econômico. Novas indústrias, baseadas na informação, exploração oceânica e novos materiais, transformarse-ão na principal força motriz do crescimento. Novas percepções, instituições, habilidades e práticas, serão necessárias para enfrentar os desafios da próxima e emergente "age of discontinuity". 8

Enquanto o enfoque principal dos supramencionados analistas converge para os países industrialmente avançados, sobretudo os Estados Unidos, as nações em desenvolvimento não podem ficar marginalizadas e fugir às conseqüências dos acontecimentos que se desenrolam nessas sociedades. Aliás, a taxa de mudança desses últimos, embora não sendo da mesma magnitude que a das nações industrialmente avançadas, é fenomenal em relação às suas anteriores e primitivas condições. De fato, a arrancada de uma sociedade agrária para o desen. volvimento econômico pode representar uma "descontinuidade" semelhante, ou, talvez, ainda mais séria do que-a transformação de uma sociedade industrial em outra "pós-industrial". 
O impacto dessas forças criou uma nova escala de problemas. As forças liberadas pela ciência e tecnologia não respeitam fronteiras locais ou nacionais; algumas delas abrangem o mundo inteiro enquanto muitas outras adquirem proporções nacionais. A preocupação com a ambiência humana, decorrente do perigo da poluição da biosfera é um exemplo bem característico. A precariedade e insuficiência das comunidades locais para resolver seus próprios problemas, sejam de transporte, comunicações, emprego ou desenvolvimento comunitário, são exemplos que ilustram a escala das novas condições. Os problemas, além disso, tornam-se crescentemente interrelacionados. O desenvolvimento agrícola, além de afetar as comunidades rurais, também modifica os problemas das cidades através das migrações, da transferência de pobreza das áreas rurais para as urbanas, e da rutura das organizações sociais. A tecnologia arroja os seus impactos sobre a ambiência biológica, ecológica e social do homem.

Os próprios governos se encontram no meio do turbilhão desencadeado por essas forças. Quaisquer que sejam os motivos, inclusive considerações morais, intelectuais e filosóficas, é incontestável a ocorrência de modificações básicas no papel dos governos. Eles já não mais reagem com a mesma simplicidade, no contexto da regulamentação tradicional, mas chamam para si mesmos a responsabilidade total no concernente à direção ou comando dos processos de mudança. Os conceitos de "interesse público", "bem-estar geral", e "benefício líquido para a sociedade como um todo" tornam-se os critérios fundamentais da ação pública. O planejamento é agora reconhecido como uma legítima função estatal em, praticamente, todos os países. Os instrumentos podem variar entre eles, mas todas as nações tentam elaborar uma visão do futuro e dão os passos necessários para atingi-lo ou realizá-lo. Todos os países se preocupam com os problemas da mudança, quer se trate de uma sociedade agrária para uma industrial, ou de uma industrial para outra do tipo "pós-industrial". Muitas são as nações que se defrontam com forças e problemas gerados pela revolução industrial: ao experimentar fazer a transição, elas verificam que os enfoques e técnicas de que podem dispor são escassamente suficientes e adequados para o tratamento dos problemas que as afligem. Tal situação obrigam-nas a buscar recursos ou meios que possam melhorar sua capacidade administrativa, a fim de tirar proveito das excepcionais oportunidades disponiveis no tocante ao desenvolvimento $\mathrm{e}$, ao mesmo tempo, transacionar 
com os aspectos negativos da conjuntura e as imprevisíveis conseqüências de políticas e ações do passado. Ao assumir a responsabilidade pública pelas várias funções, cuidam os governos de remover ou aproveitar limitações e incentivos disponíveis, conforme o caso, quando tomam decisões acerca de políticas, planos, programas e alocação de recursos. As funções relegadas ao setor privado foram-se tornando crescentemente vulneráveis à regulamentação pública, à medida que as forças do mercado se evidenciavam inadequadas, ou mesmu hostis, à consecução dos objetivos sociais. No desempenho de suas novas atribuições, o Estado, além de aumentar o tamanho e a complexidade dos negócios públicos, busca descobrir novos enfoques e técnicas de gestão. E, neste sentido, recorre, em primeiro lugar, às fontes científicas e tecnológicas que ocasionaram todas as complexidades e desafios emergentes.

Os sucessos da ciência e da tecnologia popularizaram os métodos científicos com sua ênfase no concernente à racionalidade e ao empirismo. A ciência e a tecnologia multiplicam a capacitação e potencialidades humanas, quer para propósitos construtivos como, igualmente, para finalidades destrutivas. Com a tecnologia disponiveı é possivel alimentar e vestir o mundo inteiro. A tecnologia da comunicação atingiu o estágio em que, por toda a parte, gente de todo o mundo pode se ligar num sistema global de visão e som. Os computadores aumentaram enormemente a capacidade e as potencialidades intelectuais humanas, habilitando-as a enfrentar problemas de magnitude e complexidade inéditos. As realizações concretas da ciência e da tecnologia despertaram enormes expectativas quanto à sua contribuição para a melhoria da qualidade da vida. Os países em desenvolvimento querem obter a mesma espécie de abundância que os países industrialmente avançados estão desfrutando no momento. Sustenta-se, nestes últimos, com intensidade crescente, que se a ciência e a tecnologia podem desembarcar um homem na lua, por que não podem atacar e resolver. em definitivo, os problemas aqui na terra? As espetaculares realizações da tecnologia na criação de sistemas físicos ocasionam esperanças de que, adequadamente orientada, poderão ser aprestadas para resolver os problemas sociais. Como as prioridades nacionais dos estados se movimentam no sentido da solução dos problemas sociais, os cientistas são solicitados a transferir para os mesmos sua atenção e energias, a fim de que possam resolvê-los, tornando-se, destarte, socialmente relevantes. Enquanto as potencialidades das ciências naturais e 
da tecnologia são mais evidentes ao criarem problemas e, ao resolvê-los, possibilitar a melhoria das condições de vida, a contribuição das ciências sociais é não menos decisiva. De fato, as ciências sociais contribuíram enormemente para compreensão e evolução da infra-estrutura institucional, das metodologias analíticas e sistemas de informações indispensáveis ao progresso científico e tecnológico. O aparecimento dos computadores enfatizou ulteriormente a importância destes, e de outros assuntos correlatos. Os computadores diferem das máquinas industriais porquanto são incapazes de produzir bens ou serviços. Seu uso para qualquer propósito está na dependência de insumos elaborados por uma variedade de pessoas bem versadas no desenvolvimento do "software" - baseado em modelos matemáticos e conhecimento da natureza das interações entre as variáveis pertinentes. (Software... "complexo operacional das instruções ordenadas que constituem a programação de um sistema informático; tudo que contribui para por em marcha um conjunto eletrônico").

As conquistas e a expansão da tecnologia exigem organizações e gerência mais sofisticadas a fim de que possam ser mais produtivas. Também neste caso a contribuição das ciências sociais é indispensável. A medida que os sistemas homemmáquinas avultam como os estilos predominantes de ação nas sociedades, as ciências naturais e sociais devem atuar conjuntamente. De um certo modo, elas estão tão entrelaçadas que, ou se movimentam sinergicamente juntas para a frente ou, simplesmente, não andam. O uso da ciência e da tecnologia no ataque aos problemas sociais sublinha, além disso, a necessidade de estreitas relações entre as ciências naturais e sociais. Os fecundos interrelacionamentos entre diferentes ciências e disciplinas, notadamente nos domínios das ciências sociais, constituem um poderoso fermento, agente transformador ou estímulo. Os mais recentes enfoques e sistemas administrativos são, em sua maior parte, produto dessa interação.

\section{Técnicas e Enfoques da Administração Moderna}

Os modernos enfoques e técnicas administrativas compõem um amplo e abrangente espectro de conceitos, metodologias, instrumentos e tecnologias. Essa tendência inevitável resulta, até certo ponto, da natureza multidimensional da administração que a compele a recorrer a uma enorme variedade de assuntos e disciplinas. O principal agrupamento ou aglome- 
rado de matérias acadêmicas dos quais a administração moderna se utiliza para elaboração de seus conceitos, enfoques e técnicas, incluem: I) as ciências físicas e naturais; II) as ciências biológicas; III) as ciências matemáticas; e IV) as ciências sociais e do comportamento. Os principais temas e disciplinas que mais diretamente se vinculam à administração incluem, entre outros, Engenharia Industrial, Adminístração Industrial, Administração de Empresas, Contabilidade e Finanças, Comércio, Direito, Administração Pública. Eles refletem, em considerável extensão, a organização de assuntos e disciplinas à medida que foram emergindo em resposta aos axiomas e preceitos de uma sociedade industrial Mais recentemente, disciplinas como Pesquisa Operacional e Ciência da Administração acabaram sendo reconhecidas e definitivamente estabelecidas. Entre as Ciências Sociais, a Economia tem sido mais influente e politicamente orientada no concernente ao processo de tomada de decisões públicas do que qualquer outra disciplina. As outras ciências sociais e do comportamento estão gradualmente se tornando relevantes para a política e a administração, embora o seu impacto permaneça algo limitado. ${ }^{9}$

Aquelas disciplinas muito contribuíram para o desenvolvimento das concepções e técnicas da administração moderna. Gradualmente, contudo, está-se reconhecendo que a solução dos problemas não se presta, por si mesma, a ser isoladamente conhecida e resolvida em termos unilaterais. O tratamento insulado dos problemas revela-se inviável, na prática. Esse fato originou um movimento no sentido do estabelecimento de enfoques interdisciplinares para solução dos problemas. A Pesquisa Operacional e a Ciência da Administração já foram mencionadas como exemplos de enfoque interdisciplinar. Uma nova ciência da praxeologia passou a existir. ${ }^{10} \mathrm{~A}$ fusão de diferentes ciências e disciplinas deu nascimento à Cibernética. $11 \mathrm{~A}$ despeito dos avanços no rumo da integração, ainda é muito longo o caminho a ser percorrido no concernente à plena operacionalização dos conceitos interdisciplinares.

Em virtude de se encontrarem tais ciências e disciplinas, em sua maioria, rapidamente crescendo e cada vez mais interessadas na administração, também as modernas concepções e técnicas de gestão se encontram em plena expansão. As técnicas predominantes estão sendo constantemente revisadas e requintadamente aperfeiçoadas. Novas técnicas estão sendo de. 
senvolvidas. Este processo tende a prosseguir em virtude da natureza mutável dos problemas, dos contínuos avanços no conhecimento, e da transformação das noções sociais e administrativas dos problemas e respectivas soluções.

Pesquisa Operacional, Ciência da Administração, Cibernética, Análise de Sistemas, Análise de Custos e Benefícios, Sistemas de Planejamento, Programação e Orçamento (PPBS), Programação Linear e Dinâmica, Teoria das Filas, Teorias da Decisão, Heurística, Previsão Tecnológica, Prospectiva, Planejamento de Redes, Teoria dos Jogos, para mencionar apenas alguns termos, ilustram a profusão do que se tornou conhecido como técnicas administrativas modernas. A Ciência do Comportamento contribuiu com seus próprios conceitos e terminologias. Muitas dessas técnicas se utilizam dos avanços na tecnologia dos computadores que, por sua vez, acrescentou seu próprio glossário. Em sua maioria, as ciências administrativas e disciplinas correlatas desenvolveram vocabulários específicos, os quais não tornam mais fácil o problema da comunicação. $\mathrm{Na}$ literatura da Ciência da Administração - Pública ou de Empresas - fica-se submerso com essa pletora de disciplinas, - heurística, estocástica, PERT, árvores de decisão, filas e assim por diante. Complica-se, além disso, o problema, pelo fato de que a maioria das técnicas não são mutuamente exclusivas e, além de compartilhar das respectivas características, ainda apresentam sutis distinções nos seus enunciados, suposições e ênfases. O de que se precisa é de uma taxonomia da administração. Essa taxonomia administrativa seria útil, tanto para os especialistas e pesquisadores, como, também, para os administradores que poderiam, destarte, achar mais fácil identificar e compreender as técnicas pertinentes aos seus problemas. ${ }^{12}$

Não obstante a multiplicidade de sua nomenclatura, as concepções e técnicas da moderna administração podem ser divididas, para os fins deste artigo, em dois conjuntos ou grupos que denominaríamos: I) Ciência da Administração; e II) Ciência do Comportamento. ${ }^{13}$ Embora ambos os grupos compartilhem certos aspectos comuns, tais como ênfase no método científico e na identificação de padrões subjacentes de sistemas, eles focalizam aspectos diferentes da realidade, examinando-os de ângulos ou perspectivas diversas. Cada um dos dois grupos tem características distintas para as quais voltamo-nos, a fim de evidenciar suas implicações para a administração pública. 
O complexo agregado referido como Ciência da Administração forceja no sentido de se desenvolver com maior objetividade no roteiro da quantificação. Reconhecendo que são funções intelectuais básicas da administração a formulação de políticas, a tomada de decisões e o controle, a Ciência da Administração acentua, prioritariamente, as capacidades, habilidades e metodologias que possam assessorar um gerente ou administrador no eficaz desempenho dessas funções. ${ }^{14}$ No lugar do palpite, da suposição e dos julgamentos de valor, procura por em prática "uma habilidade e metodologia originalmente desenvolvidas para pesquisa e investigação da própria natureza do trabalho e das atividades administrativas". 15 Começando com a máxima de Lord Kelvin: "o que quer que exista, existe em alguma quantidade, e pode conseqüentemente ser medido", a Ciência da Administração investiga padrões no funcionamento dos sistemas, experimenta quantificar as variáveis envolvidas, constrói modelos e procura predizer os efeitos das linhas alternativas de ação. Problemas imprevisíveis são pesquisados para resolução através da aplicação da teoria estatística das probabilidades. Conseqüentemente existe uma profusão de técnicas e modelos matemáticos aplicáveis nos diferentes campos da administração; por exemplo, problemas de levantamento, inventário, cadastro, divisão proporcional, pesquisa, filas, redes e outros semelhantes. Enquanto se reconhece ser raramente disponivel a informação completa sobre um determinado problema, a Ciência da Administração tem um voracíssimo apetite por dados, e enfatiza a necessidade que os tomadores de decisão têm de possuir uma oportuna, exata e completa informação, sobre a situação-problema a ser solücionada e das suas possíveis alternativas.

Ao identificar as variáveis e as relações causais entre elas, a Ciência da Administração utiliza os enfoques sistêmicos e a análise de sistemas. O enfoque sistêmico de um problema implica a compreensão e exame abrangentes de todos os aspectos, ou ângulos pertinentes. A definição de um "sistema" é, no mais alto grau e, fundamentalmente, uma função do problema a ser resolvido. ${ }^{16} \mathrm{~A}$ análise de sistemas compreende o exame integral das atividades, procedimentos, métodos, processos e rotinas, pertinentes ao sistema, tendo em vista identificar os possíveis efeitos e a determinação do curso de ação para atingir as conseqüências e objetivos colimados. 
A disponibilidade de computadores grandemente facilita os cálculos que são básicos para a Ciência da Administração e possibilita, igualmente, solucionar problemas que envolvem uma multiplicidade de variáveis.

Com a ajuda de computadores é possível construir modelos complexos, e manipulá-los, através do processo da simulação, que substitui os testes científicos de laboratório nas ciências naturais e biológicas.

Um dos atributos de um sistema é que tudo que é por ele abrangido é interrelacionado. Segue-se que se uma parte do sistema é mudada, todas as demais partes são também afetadas. O enfoque sistêmico põe em evidência os interrelacionamentos das variáveis do sistema, e a necessidade de pensar em termos da totalidade, ou globalidade, dos efeitos das decisões. Esse enfoque também demonstra que as pretensões e expectativas da intuição e do senso comum acerca dos efeitos das decisões são, freqüentemente, erradas. A análise de sistemas, ao mesmo tempo em que emprega enfoques interdisciplinares para a solução dos problemas, levanta difíceis questões a respeito das fronteiras ou limites dos sistemas, do delineamento das partes componentes e sua integração, da interação e interdependência entre variáveis, e sua duração ou alcance de vida. Os sistemas são, geralmente, representados por modelos. A orientação das técnicas e enfoques administrativos coexiste, como disciplina, com a existência de uma grande variedade de modelos utilizados para representar sistemas. De fato, existem mais modelos do que disciplinas. A atividade de construção de modelos na Ciência da Administração despertou considerável atenção e, freqüentemente; se emprega a Teoria Geral dos Sistemas para assinalar a hierarquia dos modelos e estabelecer sua validade.

$\mathrm{Na}$ Ciência da Administração, o conceito de utilidade, dos economistas, tem sido a pedra de toque das ações humanas e as técnicas de gestão foram projetadas, em sua quase totalidade, com vistas a facilitar a "otimização" da utilidade. Por outras palavras, estas são técnicas economicamente orientadas que centralizam sua atenção em exsumos, produtos e resultados. Elas procuram aumentar a aplicação da racionalidade, preponderantemente em termos econômicos, ao processo decisório e à tomada de decisões. Atualmente, com a crescente preocupação pelas conseqüências secundárias e terciárias das decisões, baseadas em critérios puramente econômicos e técnicos, prosse- 
gue a investigação visando incorporar critérios mais amplos à análise de sistemas. Mas, novamente, o enfoque predominante consiste em atribuir valor econômico às conseqüências secundárias e terciárias.

Os próprios conceitos e técnicas da análise econômica estão sofrendo transformações. As técnicas econômicas vinculadas à gerência dos negócios monetários e orçamentários são, no momento, amplamente empregadas em muitos países do mundo. A análise custo-benefícios tem-se tornado instrumento padrão, razoavelmente empregado, na avaliação de uma grande variedade de projetos públicos. A análise custo-benefícios representa uma grande melhoria sobre a avaliação financeira convencional pelo fato de que ela também experimenta abordar a questão dos custos e benefícios sociais associados com um projeto. Isto veio situar a questão da mensuração dos custos e benefícios sociais na vanguarda das discussões na administração pública ${ }^{17}$. O segundo aglomerado de técnicas gerenciais, por exemplo, aquelas baseadas na Ciência do Comportamento, mostram, igualmente, entre si, grandes variaçōes mas apresentam, em toda sua extensão, algumas semelhanças gerais. ${ }^{18}$. São técnicas que evidenciam, com maior destaque, o comportamento individual e organizacional. Elas atribuem grandes importância à pesquisa empírica acerca do comportamento individual e organizacional, a fim de exibir suas implicações para o desempenho dos indivíduos e das organizações, e desenvolver técnicas de intervenção capazes de provocar mudanças naquele comportamento.

A Ciência do Comportamento é essencialmente eclética, e se utiliza de quase todas as ciências sociais, incluindo antropologia, psicologia, psicologia social e sociologia. Ela tem contribuído com uma variedade de termos, tais como relações humanas, psicologia industrial, aconselhamento pessoal, motivação, moral, treinamento de sensibilidade, dinâmica de grupo, dramatização, incidente crítico, entrevista não dirigida, administração participativa, desenvolvimento organizacional, para mencionar apenas alguns exemplos. A Ciência do Comportamento encara a organização como um sistema social no qual o papel dos individuos é governado por um grande número de fatores, dos quais, nem todos, podem ser explicados em termos de racionalidade econômica. O desempenho individual é influenciado pela ambiência social, pela caracterização psicológica, pelos padrões de comunicação na organização e as relações interpessoais. 
Uma contribuição fundamental da Ciência do Comportamento tem sido o enfoque e concepção do papel do indivíduo na organização. No apogeu da teoria da organização formal e dos organogramas, a Ciência do Comportamento elaborou sua contribuição com o conceito de organização informal. A organização informal refere-se aos padrões associativos de indivíduos que, trabalhando em uma organização, não se adaptam aos organogramas. Significa evolução "natural" de relações numa situação de trabalho de grupo em correspondência com as necessidades sociais. Foi demonstrado que a colaboração não é apenas inteiramente uma questão de organização lógica, mas pressupõe códigos sociais, convenções e respostas antecipadas. A Ciência do Comportamento esclareceu, também, as implicações dos assaz conhecidos princípios organizacionais, tais como divisão do trabalho e especialização. Os fenômenos de fadiga, monotonia, sentimento individual de isolamento, sensação de anonimato e de insignificância têm sido atribuídos à aplicação daqueles principios nas organizações. Eles afetam a motivação humana, a moral e o desempenho. A Ciência do Comportamento contribuiu com um vasto elenco de conhecimentos a respeito de motivação, moral, supervisão, liderança, relações humanas, comunicações e coordenação. Proporcionou, de um modo geral, uma substancial contribuição à teoria da organização.

O desenvolvimento administrativo e a aprendizagem organizacional foram objeto de algumas contribuições essenciais da Ciência do Comportamento. Aprendizagem e solução de problemas săo conceitos psicológicos e um certo número de técnicas de treinamento e educação aplicadas pela Ciência do Comportamento transformaram, radicalmente, conceitos e enfoques aplicados ao desenvolvimento administrativo e à aprendizagem organizacional. A situação atual, nesse campo, está bem refletida nas discussões acerca de desenvolvimento organizacional (OD). Enquanto o desenvolvimento organizacional ainda significa diferentes coisas para diferentes pessoas, a capacidade e as virtualidades das organizações para resolver problemas estão rápida e crescentemente emergindo como o seu tema nuclear. ${ }^{19}$

A interação entre os dois complexos agregados de técnicas tem sido algo limitada. As conclusões lógicas da Ciência da Administração e da Ciência do Comportamento, quando levadas em consideração, nem sempre são compatíveis porque manifestam uma significativa diferença em suas respectivas suposições e 
sistemas subjacentes de valores. A Ciência do Comportamento tem revelado mais aptidão ao considerar métodos e recursos para incorporar as metodologias e descobertas da Ciência da Administração ao bojo dos seus postulados. A Ciência da Administração, ao contrário, embora cada vez mais cônscia da importância do comportamento não econômico, tem sido incapaz de assim proceder, seja por causa das dificuldades de quantificação de tais valores, ou pela relutante hesitação em conceder um "status" genuinamente científico aos postulados da Ciência do Comportamento. Do ponto de vista do administrador, contudo, ambos os grupos de técnicas de gestão permanecem importantes e oferecem perspectivas no sentido de aumentar a capacidade $\mathrm{e}$ as potencialidades administrativas para o desenvolvimento econômico e social.

\section{Uso na Administração Pública}

Os Sistemas Administrativos, nos diferentes países, mostram uma grande variedade quanto ao emprego das técnicas administrativas modernas. Poucos países assimilaram ou rejeitaram integralmente todas essas técnicas. Em uma extremidade estão países como os Estados Unidos da América nos quais o uso das técnicas da moderna administração se encontra razoavelmente difundido. Por exemplo, a tecnologia dos sistemas tem sido extensivamente utilizada nos programas espaciais e de defesa. Há, também, muitos exemplos de aplicação das modernas técnicas administrativas nas áreas dos problemas civis, tais como desenvolvimento de recursos naturais, planejamento dos transportes, administração de pessoal, recursos humanos e planejamento de empregos, uso da terra, execução do direito, jurisprudência. Existe, atualmente, grande interesse na possibilidade de aplicação de tais técnicas a outras áreas como, por exemplo, controle da poluição ambiental, planejamento educacional, administração da justiça, desenvolvimento comunitário e renovação urbana. ${ }^{20}$

Certas técnicas e enfoques administrativos - O Sistema de Planejamento, Programação e Orçamento, o PPBS, por exemplo, foram aplicados no Governo Federal.

As nações em desenvolvimento, todavia, estão situadas, em sua maioria, no outro extremo. Algumas delas ainda se encontram no estágio inicial. Outras adotaram um enfoque atomístico, fragmentado. Freqüentemente, emergiram algumas organizações, 
agências pioneiras ou exploratórias, no uso das técnicas da moderna administração. Órgãos de planejamento, repartições censitárias e empresas públicas empregaram técnicas pertinentes a seus problemas. Todavia, a aplicação generalizada de técnicas administrativas tem sido algo limitada. O "Planning, Programing, Budgeting System - PPBS" é, talvez, a única técnica administrativa moderna que atraiu a atenção da maioria dos paises e tem sido efetivamente experimentada em algumas poucas nações, com os mais diversos resultados.

Falando de uma maneira geral, debates estão sendo levados a efeito em muitos países do mundo, no tocante às possibilidades e problemas oriundos da utilização das novas técnicas administrativas na administração pública. Enquanto alguns administradores aceitaram, pelo menos no plano intelectual, indiscriminadamente, enfoques e técnicas administrativas modernas, e a respeito delas cultivam exageradas expectativas, outros continuam céticos quanto ao êxito de sua aplicabilidade aos problemas com os quais se defrontam. A exploração integral do potencial das técnicas e enfoques administrativos na administração pública exige respostas a um certo número de perguntas. Há uma crença largamente generalizada de que as novas técnicas administrativas, atualmente existentes, estão mais ligadas, ou aplicam-se melhor a problemas de tática, do que aos de estratégia: a problemas de operações mais do que aos de formulação política; a enfoques vinculados à tomada de decisões mais do que à execução de mudanças estruturais; mais aos problemas passíveis de quantificação do que aos menos ou aos não-quantificáveis; aos problemas altamente estruturados do que aos não estruturados; e aos mais limitados e facilmente definíveis do que aos meta-problemas de crescente complexidade que desafiam definições simplistas ou estreitas. Enquanto muitos problemas quotidianos de desenvolvimento são passíveis de soluções através do emprego das técnicas administrativas convencionais, os grandes problemas menos estruturados são os que exigem técnicas mais refinadas, além do "status quo" melhorado ou racionalizado. Esforços criadores são necessários para desenvolver enfoques e técnicas gerenciais aplicáveis aos grandes problemas. Ao mesmo tempo, há necessidade de uma abordagem mais realística no tocante às áreas de aplicação dessas técnicas, no caso em que excessivas exigências acerca de suas realizações provoquem ou ocasionem a rutura de todo o movimento. Compreendem-se como legítimos desafios na administração pública a formação, fortalecimento e ampliação das capa- 
cidades adequadas aos serviços públicos modernos, em condições de enfrentar problemas de mudança e desenvolvimento.

Os serviços públicos têm de operar no contexto de leis e processos políticos. O rendimento dos serviços públicos nem sempre se adapta a medidas quantitativas. Os múltiplos e variados objetivos da administração pública, por sua vez, nem sempre estão em harmonia uns com os outros. Apesar dos sistemas administrativos públicos passarem a incluir empresas econômicas e industriais, seu interesse preponderante deverá consistir mais na prestação de serviços à sociedade do que na obtenção da eficiência pura. Em última análise, valores humanos e objetivos sociais devem permanecer como critérios fundamentais na administração pública. Por todas essas razões ocorrem certas limitações no emprego das novas técnicas administrativas disponíveis na administração pública. Isto não é um grito de desespero, ou obstrucionismo, da parte dos administradores que preconizam esses pontos de vista. Trata-se de mais um desafio aos técnicos de administração para anular as limitações quanto à aplicação à administração pública das técnicas de gestão disponíveis, identificar as áreas aonde o seu uso resultaria num rendimento máximo e, o que é mais importante, desenvolver novos enfoques e técnicas especificamente aplicáveis aos problemas da administração pública.

A natureza excessivamente acadêmica de muitas das técnicas administrativas propostas é outro aspecto a ser considerado. A tradução dessas técnicas em ação exige sua simplificação e adaptação às realidades dos casos concretos. Ocorre, também, que o uso das técnicas da moderna administração tem, correlata e freqüentemente, conduzido ao estabelecimento de serviços auxiliares altamente especializados, cujas recomendações podem ou não exercer forte impacto, tanto sobre os formuladores de política como sobre os administradores.

As possibilidades e os problemas decorrentes da aplicação das modernas técnicas na administração pública podem ser ilustradas pelo exame crítico do atual emprego dos principais agrupamentos, já mencionados, e que foram aqui reunidos sob a denominação de Ciência do Comportamento, PPBS (Sistema de Planejamento, Programação e Orçamento), Processamento Automático de Dados, Sistemas Informacionais Computadorizados e Pesquisa Operacional. 


\section{Técnicas da Ciência do Comportamento}

Existe uma crescente insatisfação com as tradicionais organizações ou sistemas burocráticos no que se refere ao tratamento dos problemas de desenvolvimento e mudança. O modelo burocrático na administração pública, com sua ênfase na hierarquia, nas rotinas, nos processos e papéis formalmente prescritos, tem sido criticado como limitando a adaptabilidade, a inovação e a criatividade, tanto dos indivíduos como das organizações. Muito se tem cogitado no sentido de avançar dos modelos burocráticos para os modelos "transburocráticos". ${ }^{21}$ Mas, para que realmente servem os novos modelos e o que exatamente significam? E, como podem os sistemas administrativos passar do modelo convencional para sistemas organizacionais mais adaptativos? Até que extensão a natureza legal e política da administração pública coloca problemas de transformação dos sistemas burocráticos convencionais em novos sistemas organizacionais? É verdade que essas questões surgiram e continuam brilhando no cenário da Ciência do Comportamento, mas, o impacto provocado no interior das estruturas existentes tem sido limitado. O avanço para 'sistemas de administração participativa e a utilização de técnicas participatórias continuam, todavia, recebendo crescente atenção. Afirma-se que a administração participativa como um sistema, estilo e clima organizacional, promove mobilização do esforço, a ativação de grupos e indivíduos passivos e a melhoria da motivação e da moral. A administração participativa enfatiza a cooperação entre indivíduos dentro das organizações, entre as próprias organizações e entre as organizações e os respectivos ambientes (ecosistemas). O movimento realça a atuação dos indivíduos nas organizações e um certo número de técnicas conhecidas como desenvolvimento organizacional (OD) surgiram para uso limitado.

As técnicas da Ciência do Comportamento estão provocando um impacto, especialmente no concernente ao treinamento para o desenvolvimento administrativo e são, por sua natureza, etnocêntricas. Pouca informação é disponivel sobre elementos dos sistemas de valores sociais e culturais pertinentes ao desempenho gerencial sob diferentes contextos. O comportamento individual é determinado por uma variedade de fatores entre os quais os valores sociais e culturais são extremamente importantes. Grande parte da pesquisa em Ciência do Comportamento tem sido levada a efeito nos países industrialmente avançados, os quais podem ter padrões de valores 
sociais e culturais diferentes daqueles dos países em desenvolvimento. Existem, também, diferenças perceptíveis entre os países, quer sejam ou não, industrialmente desenvolvidos. Neste contexto, a evolução e adaptação das técnicas de administração especificamente engendradas, ou modeladas, para diferentes meios culturais, tornam-se importantes.

\section{Sistema de Planejamento, Programação e Orçamento (PPBS)}

Os elementos chaves no PPBS são a programação orçamentária e a análise de sistemas. A programação orçamentária sob qualquer denominação e as técnicas correlatas de análise econômica têm recebido, em muitos países, considerável atenção.

A orçamentação convencional - com seus objetivos de despesas formalizadas num documento - tem sido objeto de críticas, pelo fato de concentrar sua atenção, no tocante às atividades governamentais, apenas em termos de seus respectivos custos e despesas, sem cogitar de um correlacionamento mais estreito com os resultados esperados. Ela não se presta ou inclina para uma distribuição mais racional de recursos ou sua utilização alternativa mais eficaz. Supõe-se que tenha um certo preconceito contra os novos programas. Por outro lado, o PPBS é considerado mais conveniente e adequado ao promover a administração por objetivos e o controle pelos resultados. $O$ advento do planejamento e a resultante necessidade de integrar as práticas de planejamento e programação com as práticas orçamentárias têm, além disso, acentuado a necessidade e promovido a execução de reformas orçamentárias. Estas considerações grandemente encorajaram o Sistema de Planejamento, Programação e Orçamento (PPBS) às análises de custo-benefício e custo-eficácia na administração pública.

O conceito nuclear do Sistema de Planejamento, Programação e Orçamento (PPBS) é baseado na definição do orçamento como um problema de distribuição e divisão proporcional de recursos no sentido econômico. As metodologias derivadas desse conceito do problema acarretam, essencialmente, uma precisa definição de objetivos, desenvolvimento de critérios para quantificação ou medida, identificação de meios e recursos alternativos para alcançar estes objetivos, projeção de seus custos e benefícios futuros e uma justificação racional para as alternativas mais satisfatórias. 
As dificuldades implícitas no emprego de novas técnicas e sistemas orçamentários são muitas. Elas se referem à incorreção e inadequação da denominação e classificação das atividades governamentais, exclusão de efeitos não-quantificáveis, conexões desajustadas entre recursos, atividades e resultados, as dificuldades de prognosticar parâmetros temporais, dimensionar custos e benefícios futuros e avaliar taxas adequadas.

Enquanto algumas variações do Sistema de Planejamento, Programação e Orçamento (PPBS) têm sido auspiciosa e vantajosamente empregadas em negócios geradores de renda no setor público, seu impacto nos departamentos governamentais tem sido, porém, limitado. Algumas vezes têm gerado mais dificuldades do que facilidades quanto ao aperfeiçoamento do processo de tomada de decisões. Muito freqüentemente o sistema tem sido enxertado nas estruturas e práticas existentes contribuindo, apenas, para aumentar processos e papéis.

A introdução destas técnicas levantou, também, questões acerca da natureza política do orçamento, e a extensão em que o emprego do PPBS e técnicas correlatas podem se harmonizar com os processos políticos e legislativos pertinentes à orçamentação governamental. ${ }^{22}$

Muitos países continuam tolerando sistemas ineficientes de informações e contabilidade os quais, são, contudo, essenciais à aplicação destas técnicas.

A discussão de novos sistemas orçamentários tem sido mais auspiciosa ao focalizar atenção sobre a exata definição e rendimento dos programas governamentais, sobre a desejabilidade de aumentar a racionalidade no tocante ao uso de recursos escassos, e a utilização do orçamento como indispensável instrumento de gestão.

O emprego das análises custo-benefício e das técnicas condensadas no binômio insumo-exsumo tem sido bastante útil como contribuição ao aumento da capacitação analítica na administração pública.

Em termos operacionais, estas técnicas demonstraram sua eficácia como instrumentos de planejamento e implementação de projetos e programas. Combinadas com as subfamílias das análises de redes, levantamento, inventário e listagens diversas, 
proporcionaram aos administradores instrumentos potencialmente poderosos para elaboração de projetos viáveis e sua execução sem atrasos evitáveis, obtenção de eficiência e economia na respectiva execução, e previsão de medidas quanto a possíveis eventualidades. A utilidade destas técnicas foi demonstrada em inúmeras auspiciosas experiências, coroadas de êxito, especialmente em projetos envolvendo complexos programas de engenharia, construção e produção.

\section{Processamento Automático de Dados (ADP) e Sistemas Computadorizados de Informações}

O emprego de computadores está se generalizando na administração pública. Os países industrialmente desenvolvidos fizeram rápidos progressos na aquisição e utilização de computadores para o setor público. Os países em desenvolvimento também adquiriram computadores para emprego em alguns setores e estão engajados na solução das questões decorrentes de sua introdução.

Em muitos sistemas de administração pública o computador está sendo inicialmente utilizado para automação de certos processos administrativos. Diversas grandes empresas públicas empregam computadores em conexão com suas atividades de produção, na administração de logística, inventários e controle de estoques. Entre os departamentos governamentais, as agências de estatísticas geralmente assumiram a liderança na obtenção de computadores. Orgãos fiscais de tributação em muitos países subdesenvolvidos também computarizaram suas operações. Em outros departamentos governamentais, as aplicações dos computadores limitam-se, freqüentemente, à mecanização de contas, confecção e processamento de folhas de pagamento.

A utilidade dos computadores na administração pública tem sido amplamente aceita e muitas das questões versam em torno da atual aquisição do "hardware", desenvolvimento da capacitação e competências nos sistemas administrativos para o uso eficaz dos computadores e classificação dos problemas oriundos do seu emprego (Hardware - Complexo físico das instalações de um sistema informático, composto de uma unidade central e de vários instrumentos periféricos; designa a constituição física, os componentes tangiveis e materiais de um sistema eletrônico). No começo, ao que parece, os computadores foram adquiridos, em muitos casos, por todas as espécies de 
razões, incluindo seu valor como símbolo de prestígio (status). Ocorreram inúmeros casos dos computadores não serem utilizados e outros de subutilização, nas organizações públicas, enquanto muitas outras estão exigindo aquisição de novos computadores. Como a decisão de adquirir um computador acarreta, muitas vezes, conseqüências nacionais os governos estão crescentemente se conscientizando da necessidade de elaborar políticas sobre o assunto e estabelecer arranjos institucionais para regular a aquisição e utilização de computadores (Observação: este é, precisamente, o caso do Brasil ao instituir a CAPRE Comissão de Coordenação das Atividades de Processamento Eletrônico, Ministério do Planejamento e Coordenação Geral).

Os países em desenvolvimento se preocupam com o fato de que a tecnologia do computador é basicamente orientada em função das realidades das sociedades industrializadas e, portanto, nem sempre adequadas às suas necessidades. Fizeram-se sugestões no sentido de que os fabricantes de computadores levassem em consideração as necessidades dos usuários daqueles países, pelos métodos e recursos julgados convenientes.

Muitos desses países têm ainda de preparar, nos seus sistemas administrativos, pessoal competente para uso eficiente dos computadores. Além da grande necessidade de treinamento de pessoal especializado para efetiva operação e manejo das facilidades de computação, o pessoal administrativo dos aludidos países geralmente deve ser conscientizado acerca da utilização dos computadores.

As jurisdições públicas freqüentemente descobrem que os computadores são simplesmente máquinas, cujo emprego eficaz depende da definição de procedimentos e relações abrangidas pela sua operação. Os sistemas administrativos têm, por conseguinte, de ser preliminarmente esclarecidos quanto aos computadores, cuja utilização, para certos objetivos, levanta difíceis problemas de natureza política. Nos países industrialmente avançados, propostas para o estabelecimento de bancos de dados estão gerando temores a respeito da infringência da liberdade individual. Nos países em desenvolvimento as controvérsias giram em torno da tendência dos computadores para estimular a centralização; medo do desemprego entre certas categorias de pessoal; desenvolvimento de arranjos viáveis para uso ótimo de facilidades instaladas para computadores; quali- 
dade, quantidade e comunicação de informação, para mencionar apenas algumas.

A utilização de computadores como uma ajuda ao processo de tomada de decisões na administração pública ainda é restrita. Os sistemas administrativos à medida que desenvolvem sua capacidade para uso de computadores, podem, também, tirar vantagem de algumas das modernas técnicas gerenciais, dependendo das potencialidades do computador. A capacidade dos computadores para armazenamento e recuperação de grandes quantidades de informação pode revolucionar as memórias institucionais. Além de provocar mudanças estruturais promovem, os computadores, uma radical transformação das estruturas de trabalho no setor público. As virtualidades e armadilhas no emprego de computadores como um instrumento da administração, estão, aos poucos, vagarosamente, se tornando parte da consciência administrativa mas sua adoção iria muito longe promovendo o emprego eficaz e responsável dos computadores.

\section{Pesquisa Operacional}

A bateria de técnicas nesta categoria está estreitamente relacionada com o desenvolvimento da competente utilização funcional dos computadores nos sistemas administrativos.

Enquanto alguns esforços restritos, freqüentemente ineficazes, têm sido efetuados para usar a pesquisa operacional no planejamento do desenvolvimento nacional, seu emprego tem sido predominante e muitas vezes auspicioso ao micronível do departamento individual e da empresa pública.

Empresas econômicas têm sido mais condescendentes no concernente ao emprego dessas técnicas do que os organismos e instituições governamentais tradicionais. Uma razão para isso é a natureza das atividades das empresas econômicas e a possibilidade de desenvolver modelos pertinentes aos problemas de estoques, levantamentos, produção, substituições e manutenção. Para problemas envolvendo considerações estratégicas e de longo prazo, os modelos ou estão faltando, ou são difíceis de retificar e operacionalizar. Os objetivos das políticas públicas não são, algumas vezes, passiveie de definições precisas e mensurações matemáticas. Também existem difíceis problemas de quantificação de variáveis. 
A despeito destas limitações, a ênfase da pesquisa operacional na utilização de métodos científicos para solução de problemas administrativos, adotando um ponto de vista sistêmico, e a aplicação de perspectivas interdisciplinares, tem grande relevância para a administração pública. Aonde os modelos matemáticos são difíceis de construir, a simulação pode fornecer algumas úteis aproximações e sensibilizar os administradores para a espécie de questões a serem formuladas na tomada de decisões, correlacionadas com as dimensões do problema e implicações das decisões propostas.

\section{Algumas Implicações Globais}

Diversos requisitos e conseqüências da aplicação dos modernos enfoques e técnicas administrativas na administração pública foram mencionadas ou ficaram inplícitas nos tópicos precedentes. Agora, pretende-se, concisamente, indicar alguns dos efeitos globais resultantes da elaboração e uso eficaz das aludidas técnicas destinadas a aumentar a capacitação e as virtualidades administrativas para o desenvolvimento econômico e social.

De certa maneira, a opção não consiste em usar ou deixar de usar este importante recurso no campo da administração pública. O uso da tecnologia mais adequada nesse campo é imperativo, caso os governos venham a desempenhar um papel significativo no que se refere ao desenvolvimento econômico e social. A verdadeira questão é a de saber se os sistemas administrativos promoverão as ações indispensáveis à utilização das novas tecnologias de uma maneira judiciosa, sistemática e dinâmica ou, simplesmente, claudicam e sucumbem às pressões de várias espécies.

As pressões que se exercem na administração pública visando ao uso dos modernos enfoques e técnicas administrativas derivam de razões diversas: a ciência e a tecnologia carecem, para sua eficiente aplicação, no interesse dos objetivos nacionais, de equipamentos apropriados, sofisticadas organizações e sistemas gerenciais eficazes. O desenvolvimento planificado, que emergiu como uma das funções básicas da administração pública, não pode ser levado a efeito sem o auxílio de um vasto espectro de instrumentos administrativos conceituais, analíticos e técnicos. Sistemas e técnicas administrativas pertinentes são 
indispensáveis para a gestão modernizada de uma imensa variedade de empreendimentos comerciais e industriais. Da mesma forma, programas de seguro social e de bem-estar para densas populações somente podem ser administrados com o auxílio de elaborados sistemas administrativos. Atuam, também, os fatores transnacionais; considerações econômicas e tecnológicas estão assumindo o comando do processo de tomada de decisões dentro de cada país e entre as nações, em assuntos de comércio, negócios e ajuda. Nenhum país pode isolar-se destas ou de outras influências gerais e negociar, eficazmente, sem desenvolver apropriados sistemas de informações e diferentes espécies de habilidades analíticas.

Diversas ações são necessárias para assegurar o uso conveniente dos modernos enfoques e técnicas administrativas na esfera da administração pública. Na vanguarda situa-se a necessidade fundamental de mudança de orientação dos sistemas administrativos vigentes, os quais, por sua natureza, se inclinam para a estabilidade e autoperpetuação. Mas, eles já não podem mais funcionar na base do precedente e da fortuita introdução de medidas de aperfeiçoamento aleatório.

Em toda sociedade existem, naturalmente, padrões de atividade estáveis e rotinizados, assim como funções variáveis exigindo a criação de novos padrões: a predominância das primeiras capacita os líderes e administradores a centralizar sua atenção sobre os últimos. A relativa magnitude e importância de ambos, contudo, mudou significativamente, de maneira a ocasionar uma diferença qualitativa nos negócios públicos ao em vez de uma simples questão de grau.

O desafio da administração pública é acompanhar esta mudança qualitativa, razão pela qual deve enfatizar a criatividade, a inovação e a mudança dirigida. Implícito no conceito de administração da mudança está o reconhecimento da crescente taxa de obsolescência das organizações, habilidades e técnicas administrativas. Por conseguinte, a introdução dos novos sistemas e tecnologias não se pode efetuar aleatória ou unilateralmente. Impõe-se, ao contrário, a necessidade de implantar esquemas ou estruturas administrativas e éticas que valorizem a experimentação, a receptividade a novas idéias e sistemas de administração, e flexibilidade bastante para enfrentar os desafios dos ambientes rapidamente mutáveis. 
Os sistemas administrativos devem aprender a viver e sobrepujar a complexidade. Instituições e administradores individuais, avassalados ou aturdidos pelos efeitos da mudança e da complexidade são, provavelmente, pouco capazes de proporcionar uma adequada contribuição ao desenvolvimento econômicosocial.

Ações específicas são necessárias para estimular a elaboração e conveniente emprego dos mencionados enfoques e técnicas na administração pública, destacando-se, à guisa de ilustração, os imperativos de modificações radicais no que se refere à organização, às políticas de pessoal, ao treinamento e educação para os serviços públicos. Todas elas contribuem para identificar o desenvolvimento da capacitação e das competências administrativas como uma matéria altamente prioritária e urgente.

As modernas técnicas e enfoques administrativos têm poucas probabilidades de reduzir o tamanho ou importância das organizações. Pelo contrário, elas ampliam, consideravelmente, as atribuições e encargos dos sistemas organizados nos negócios públicos. A maioria das técnicas modernas de administração, particularmente aquelas baseadas na tecnologia dos computadores, somente podem ser economicamente usadas pelas organizações de grande escala. A introdução de novas estruturas institucionais e sistemas gerenciais na administração pública, - para solucionar problemas que abrangem desde politicas nacionais de ciência e tecnologia até a aplicação de tecnologias específicas para produção de bens, mercadorias e serviços, - muitas vezes envolve a criação de agências e instituições especializadas de coordenação de políticas e problemas administrativos gerais, assim como de órgãos destinados a fortalecer a capacitação funcional e operacional dos indivíduos e das organizações, no que se refere ao emprego das tecnologias pertinentes. A introdução de enfoques e técnicas administrativas modernas exige remanejamento de funções dentro das organizações, reorganização dos níveis em que as decisões são tomadas, definição e aperfeiçoamento de procedimentos e fluxos de trabalho e desenvolvimento de novos sistemas informativos.

Para ir ao encontro do problema da obsolescência, as organizações têm de se conservar flexíveis e receptivas às novas idéias e exigências. Isto é mais fácil de dizer do que de fazer. 
Contudo, vários enfoques foram sugeridos para o tratamento de tais problemas. Alguns escritores predizem que as organizações do futuro serão "Sistemas adaptativos provisórios, rapidamente mutáveis, organizados em torno de problemas a serem resolvidos por grupos de especialistas relativamente estranhos entre si, com diversas habilidades profissionais". ${ }^{23}$ Equipes multidisciplinares e grupos de trabalho poderão suplantar o trabalho dos administradores individuais na tomada de decisões. Ao levar em conta as descobertas da Ciência do Comportamento, a organização do futuro pode ser caracterizada mais pelos atributos de "sistemas sociais" e "modelos biológicos" do que pelas características dos modelos mecânicos. Os rígidos aspectos hierárquicos das organizações cederão o lugar a práticas mais participativas e igualitárias. Mudanças de longo alcance serão exigidas nos sistemas e práticas da administração de pessoal, a fim de que as potencialidades das modernas concepções e técnicas administrativas possam ser plenamente realizadas. Em primeiro lugar, isto significa a incorporação aos serviços públicos de uma imensa variedade de novos especialistas e técnicos. A introdução do processamento automático de dados nos órgãos governamentais exige, por exemplo, o emprego de analistas de sistemas, de programadores e de uma legião de engenheiros, técnicos e operadores.

Muitos sistemas administrativos ainda estão lutando com problemas de recrutamento e tentando, efetivamente, utilizar os serviços de pessoal científico e técnico. A habilidade dos serviços públicos para conseguir meios e recursos, em condições de atrair e conservar os serviços de pessoal técnico e profissional qualificado, incluindo cientistas da administração, pode ser o fator isolado mais importante no emprego das modernás concepções e técnicas administrativas. O problema é complicado pela escassez de especialistas nessas variadas técnicas, pelos níveis de retribuição dos serviços públicos quando comparados com os das empresas não-governamentais, e, freqüentemente, pela estrutura dos mencionados serviços. Embora diferentemente organizados nos diversos países, os serviços públicos foram historicamente concebidos e projetados para recrutar "cavalheiros", "gentlemen" generalistas e servidores burocratas. Subseqüentemente, muitos serviços públicos estabeleceram quadros de profissionais e técnicos. Todavia, com poucas exceções, essa tradicional orientação histórica dos serviços públicos continua a projetar a sua vasta sombra, particularmente com relação ao pessoal administrativo. Torna-se imperativa a 
elaboração de novos quadros administrativos que compreendam as modernas concepções e técnicas, e possam integrar os recursos de diferentes especialistas. Urge, igualmente, proporcionar oportunidades de formação e qualificação aos especialistas e pessoal profissional para os empregos administrativos. As estruturas de carreiras, com sua ênfase na permanência do emprego, antiguidade e sistema de pensões, tendem, freqüentemente, transformá-las em sistemas fechados, com entrada ou acesso somente possível nos níveis inferiores. Novas exigências da administração pública exigem maior mobilidade tanto internamente como entre os serviços públicos e destes com toda a sociedade. A fim de encorajar tal mobilidade as políticas de administração de pessoal terão de ser consideravelmente modificadas. Os sistemas de pessoal nos serviços públicos terão de reconhecer e enfrentar os problemas da obsolescência e da necessidade de introduzir novas habilidades e competências, através de medidas tais como o ingresso lateral nos serviços e a reciclagem dos responsáveis.

A magnitude do esforço educacional e do treinamento exigidos para promover capacitação e competência nos serviços públicos está refletida na própria amplitude das modernas técnicas administrativas. Essa magnitude abrange a educação do novo tipo de administradores públicos, a formação de uma enorme variedade de especialistas e de pessoal técnico reclamados para o manejo dos diferentes enfoques e técnicas; o treinamento e reciclagem de pessoal e a permanente educação dos administradores.

A preocupação e o interesse relativamente a esses problemas estão crescendo na órbita da administração pública; até o presente, no entanto, os programas educacionais e de treinamento para os serviços públicos ainda não se engajaram em profundidade e de maneira sistemática. A educação em administração e tecnologias administrativas tem sido mais uma prerrogativa das empresas e escolas profissionais do que das instituições da administração pública. Os serviços públicos procuraram ir ao encontro de suas necessidades utilizando-se do produto dessas entidades. Urgem maiores esforços no sentido de identificar as diferentes espécies de especialistas nas variadas tecnologias administrativas, para os serviços públicos, bem como cumpre encorajar os sistemas educacionais a fornecer, através de cursos sugestivos, o tipo de educação mais aconselhável para tais objetivos. 
A educação de administradores exige, porém, cursos não padronizados, mesmo sob o protótipo da administração de empresas. Nos Estados Unidos da América, por exemplo, há cursos superiores com ênfase "behaviorista" e especialização na teoria da organização e comportamento humano, assim como cursos em que predominam enfoques quantitativos e especialização em pesquisa operacional. Estes últimos acentuam a importância do método científico, da construção de modelos conceituais, das habilidades analíticas e da linguagem matemática. $O$ problema da educação é complicado pela falta de distinção entre desenvolvimento da administração e desenvolvimento de especialistas nas tecnologias administrativas. ${ }^{24}$

A escolha de programas educacionais para a administração e formação de especialistas em tecnologias administrativas é apenas um dos aspectos da solução desejada. Como os problemas substantivos nos negócios públicos, de um iado, e as tecnologias pertinentes à sua solução, do outro, estão rapidamente mudando, torna-se imperativo iniciar programas de educação permanente para os administradores. $O$ treinamento em serviço e a reciclagem de pessoal público são indispensáveis, a fim de manter sua capacitação funcional e profissional compatível com os papéis que deve desempenhar.

A educação e o treinamento visando a capacitar os serviços públicos a que possam se servir das modernas concepções e técnicas administrativas carecem de urgente atenção e providências imediatas. As mudanças organizacionais e de pessoal, discutidas anteriormente, serão significativas somente até 0 ponto em que se possa, de fato, obter pessoal qualificado para os serviços públicos.

Gostaria de concluir acentuando, com o relevo que merece, a importância da construção institucional - ou criação de instituições - ("institution building") para o desenvolvimento organizacional nos serviços públicos. Existe uma imperiosa necessidade de centros profissionais que possam empreender pesquisas sobre tecnologias administrativas mutáveis, definição dos problemas que devem ser resolvidos e as tecnologias administrativas mais pertinentes para esse propósito. São igualmente indispensáveis amplos programas educacionais e de treinamento em tecnologias administrativas. Funções de consulta terão de ser criadas para assistência e orientação dos administradores. Tais instituições podem ser organizadas de maneira 
a combinar propósitos diversos. Mas o ponto importante é criar organizações viáveis que possam desempenhar os encargos relacionados com o desenvolvimento organizacional, em níveis cada vez maiores de eficiência e eficácia, de tal forma que possam estimular a promoção das capacidades e competências administrativas, basicamente indispensáveis nos domínios da administração pública.

\section{REFERENCIAS BIBLIOGRÁFICAS}

1) United Nations Science and Technology for Development. Proposals for the Second United Nations Development Decade. New York, 1970 (E.70.1.23), p. 5

2) Toward Balance Growth: Quantity with Quality. Report of the United States Goals Research Staff. Washington, D.C. 1970, p. 114.

3) Ibd., p. 109

4) Ibd., p. 119. Also see Technology: Processes of Assessement and Choice: Report of the National Academy of Sciences. Washington, D.C., 1969; and A Study of Technology Assessement: Report of the Committee on Public Engineering Policy, National Academy of Engineering, Washington, D.C., 1969.

5) Ibd., p. 5

6) Alvin Toffler, Future Shock, New York, Random House, 1970.

7) Frederick Mosher, "The Public Service in the Temporary Society", Public Administration Review, N. I (Jan./February 1971), pp. 47-62.

8) Peter Drucker. The Age of Discontinuity. New York: Harper and Row, 1969.

9) See for example, Knowledge into Action: Improving the Nations Use of the Social Sciences (Report of the Special Commission on the Social Sciences of the National Science Board), Washington, D.C., 1969.

10) See for example, Arnold Kaufmann. The Science of Decision-Making: An Introduction to Praxeology. New York: McGraw-Hill, 1968; and Herbert Simon. The New Science of Management Decision. New York, Harper and Row, 1960.

11) Nobert Winer. Cyberneties: or Control and Communication in the Animal and the Machine. Cambridge, Mass, the M.I.T. Press (second edition), 1961.

12) On the importance of taxonomy and a proposed taxonomy for Operations Research, see Russell W. Fennske, "A Taxonomy for Operations Research", Operations Research (The Journal of the American Society for Operations Research), Volume 19, n. 1 (Jan/February 1971), pp. 224-234. 
13) There is no single behavioural science. Biology, Psychology, Sociology, Social Psychology and Anthropology, to name only a few, all concern themselves with individual and group behaviour. The expression Behavioural Science, in singular, is used here only for facility of discussion.

14) See Stafford Beer. Management Science. The Business Use of Operations Research. Garden City, New York: Doubleday and Company, Inc. 1968.

15) Ibd., p. 19.

16) For an introduction to systems approach, see C. West Churchman. The Systems Approach. New York: Delacorte Press, 1968.

17) See for example, H.G. Walsh and Alan Williams, Current Issues in Cost-Benefit Analysis. London: Her Majesty's Stationery Office, 1969. (CAS Ocasional Paper Number 11).

18) See Marcus, Alexis and Charles Z. Wilson. Organizational DecisionMaking. Englewood Cliffs, New Jersey: Prentice-Hall, Inc., 1967.

19) For a review of different issues in OD, see Leslie E. This, Organizational Development: Fantasy or Reality. Washington D.C., Society for Personnel Administration, August 1969 (Supervisor Booklet n. 7).

20) See Systems Technology Applied to Social and Comunity Problems. Report prepared for use of the Committee on Labour and Public Welfare, 91 Congress, First Session, Washington, D.C., 1969.

21) See for example, Warren G. Bennis, "The Leader of the Future", Public Management, March 1970, pp. 13-19.

22) For an analysis of experience in the United States of America, see Planning, Programming, Budgeting Inquiry of the Sub-Committee on National Security and International Operations for the Senate Committee on Government Operations. Washington D.C., 1970.

23) Warren G. Bennis, "The Leader of the Future", Public Management, March 1970, p. 13.

24) For an analysis of education problems in the United States, See Management Science (Journal of the Institute of Management Sciences), Volume 17, Number 2 (October 1970): Educational Issues.

\section{Observações à Margem das Novas Tecnologias Administrativas}

O emprego de novas metodologias e técnicas de gestão no âmbito da administração pública em quase todos os países vem se expandindo cada vez mais. Trata-se de uma tendência universal. Sua utilização é tanto mais necessária quanto mais decisivo se evidencia o papel da administração moderna como 
poderoso instrumento de gestão dos grandes conjuntos burocráticos. As novas metodologias evoluem e continuamente se adaptam às necessidades e circunstâncias de cada país.

Com efeito, sendo a administração um instrumento da evolução e da mudança, sua expansão resulta do jogo de múltiplas forças e acontecimentos em que sobressaem conjuntamente com as conquistas da ciência e da tecnologia, as inevitáveis transformações dos objetivos, funções e estilos de atuação do Poder Público.

Quando se fala de enfoques e técnicas da administração moderna faz-se alusão a um complexo agregado de matérias e disciplinas variáveis, segundo os pontos de vista dos principais autores - teóricos e práticos - das ciências administrativas em geral, e da administração pública ou empresarial, em partic''lar. No contexto desse agregado deve-se sublinhar a importância do papel dos computadores e da incidência da abordagem sistêmica.

Ninguém ignora o quanto e como são utilizadas nos serviços públicos as técnicas da moderna gestão embora seja difícil precisar o dimensionamento e resultados de seu emprego.

A verdade é que poucos países conseguiram assimilar a totalidade dessas técnicas, havendo alguns que ainda não tomaram conhecimento de sua existência. Os Estados Unidos, obviamente, levaram muito longe o seu emprego em diversos setores como a defesa nacional e a exploração do espaço; na esfera da administração a maior contribuição continua sendo o "Planning, Programing, Budgeting System" - o conhecido PPBS. No extremo oposto encontram-se numerosos países subdesenvolvidos que fazem tentativas parciais ou limitadas e estão praticamente na estaca zero. O emprego das técnicas mais avançadas apresentam ainda caráter experimental e em alguns casos constituem uma legítima aventura. Entre esses extremos se encontra toda uma gama de situações intermediárias.

Evidentemente muito se escreve e discute a respeito das novas técnicas: se há entre os administradores fanáticos convencidos (que se deixam por vezes carregar nas asas do sonho), também existe um grande número de céticos que manifestam suas dúvidas e frustração quando os problemas não são resolvidos a contento. Os pontos de vista podem variar de acordo 
com circunstâncias ou necessidades: certas técnicas modernas são mais úteis na escala estratégica do planejamento do que na tática, quando se opera o engajamento com os casos concretos e as exigências das realidades.

Pode-se, no entanto, afirmar que a maior parte dos problemas quotidianos de gestão podem ser resolvidos, na hipótese em que sejam utilizadas técnicas adequadas e que sua contribuição é mesmo insubstituivel no tratamento ou processamento de dados específicos para os problemas de vulto que envolvam muitas variáveis. As adaptações a cada caso são indispensáveis e carecem de aperfeiçoamentos realistas compatíveis e permanentes.

Com efeito, o setor público funciona no quadro do direito e inevitavelmente vinculado aos processos políticos. Suas atividades, - nem sempre quantificáveis ou mensuráveis, - se desenrolam nos parâmetros da normatividade técnica e jurídica. Deve-se admitir que nem todas as técnicas administrativas modernas possam ser, ao mesmo tempo, utilizadas no setor público como no setor privado e isto pela natureza mesma das coisas. As adaptações são imperativas e repelem generalidades; cumpre examinar a questão de mais perto, tendo em vista os setores específicos compatíveis com a utilização colimada.

Um primeiro domínio que exige correta avaliação é o do emprego das técnicas em função dos postulados da Ciência do Comportamento. Atualmente, critica-se cada vez mais o sistema burocrático de organização em razão de sua rigidez e de sérios inconvenientes quando é preciso demonstrar dinamismo. Pergunta-se cada vez mais se o sistema burocrático não está totalmente ultrapassado. Não seria o caso de conceber modelos "transburocráticos"? Será que isso é possível? Em caso afirmativo, como realizá-los na prática? Mas, o sistema burocrático tradicional não permanece estático: ele se abre à participação e procura remediar sua pesada carga e opressiva lentidão: Entende-se como "administração participativa" a que acentua a importância da cooperação interna nas organizações, entre organizações e com o meio social (eco-sistema). Neste caso, os postulados da Ciência do Comportamento desempenham um papel essencial pelo fato de que essas técnicas se ligam a todo um conjunto de dados sócio-culturais variáveis no contexto das sociedades industrializadas e desenvolvidas; de tal sorte que, 
fora desse contexto, sem adaptações importantes, as técnicas em apreço carecem de sentido e valor.

Um segundo domínio ou área é o da utilização do Sistema de Planejamento, Programação e Orçamento - (PPBS), do qual os elementos fundamentais são a programação orçamentária e a análise de sistemas. Sob uma ou outra forma, com diferentes denominações, a programação orçamentária progrediu um pouco em toda a parte e fez recuar os antigos métodos. O PPBS por sua vez favorece o desenvolvimento da administração por objetivos e o controle dos resultados.

A experiência nos Estados Unidos demonstra que é preciso reunir, preliminarmente, com o máximo rigor, todas as condições favoráveis (no plano, por exemplo, das informações e dos mecanismos contábeis) para o sucesso da implantação. De qualquer forma, as novas técnicas são assaz auspiciosas.

Uma terceira órbita é a da Informática. A utilização do computador estende-se, efetivamente, com surpreendente rapidez, nos serviços públicos de todos os países. É uma tendência universal e incoercível, menos por questões de "status" do que pelos imperativos dos rendimentos satisfatórios e da eficácia global dos Sistemas. Subsistem, contudo, os graves desafios da implantação, da utilização adequada e da adaptação ao computador. Esse é um vasto domínio da investigação, ainda pouco explorado, embora se constate que os poderes públicos estão procurando, em toda a parte, promover a coordenação do emprego dos computadores e o desenvolvimento de uma "política" de Informática. O Brasil, felizmente, se encontra entre as nações de vanguarda: aí está a CAPRE (Comissão de Coordenação das Atividades de Processamento Eletrônico - Ministério do Planejamento e Coordenação Geral), em pleno funcionamento.

Grande número de países subdesenvolvidos mostram-se reticentes porque muito trabalho preliminar tem de ser levado a efeito no tocante à formação de pessoal especializado e à reforma dos procedimentos e estruturas antes que se possa obter qualquer proveito do computador. Receiam eles, com razão, o reverso da medalha, ou seja, os perigos do computador, porquanto, efetivamente, os bancos de dados podem ocasionar problemas relativos à liberdade e à proteção dos direitos individuais. 
Um quarto setor a ser cuidadosamente avaliado é o da Pesquisa Operacional cujo desenvolvimento está ligado ao computador. Sua utilização permanece setorial e limitada: as empresas de caráter industrial ou comercial dispõem de mais empregos no campo da pesquisa operacional que os ministérios. Não se deve, contudo, minimizar sua importância na administração pública ou na gestão das empresas, pelo fato de que os enfoques interdisciplinares e os modelos matemáticos postulados pela Pesquisa Operacional são de elaboração difícil, ensejando problemas adicionais de simulação. Em síntese, o problema maior não consiste em saber se é ou não preciso utilizar essas técnicas, que nenhum governo responsável poderá ignorar, mas, verificar, até que ponto, os sistemas administrativos adotados, ou em vigor, podem ser adaptados ao computador.

Estes sistemas, como é notório, são, por natureza, inclinados à estabilidade, à rotina, ao medo da mudança e gradual obsolescência. A Administração moderna deve ser capaz de permanente atualização e, ao mesmo tempo, capaz de transformar o mundo exterior pelo desenvolvimento econômico e social; ela tem necessidade de espírito de criação, de dinamismo e de mudança. A adoção das novas técnicas e concepções administrativas permite avançar nesta direção e ultrapassar os obstáculos que se antepõem à modernização. Mas, a tarefa é imensa por isso que é preciso, ao mesmo tempo, atuar sobre os homens, as estruturas e os métodos, encargo que pressupõe enormes esforços, notadamente ao nível da formação e do aperfeiçoamento dos agentes. Surgem novos tipos de funcionários que devem ser preparados para o eficiente desempenho de suas missões. Na verdade, o gigantesco esforço apenas começou no terreno da pesquisa, do ensino e da experimentação concreta. 